\title{
Kayseri Piyasasında Satışa Sunulan Endüstriyel Tip Fermente, Kasap ve Isıl İşlem Görmüş Sucukların Biyojen Amin Miktarlarının Belirlenmesi
}

\author{
Yasemin Çelebi Sezer* \\ ${ }^{1}$ Osmaniye Korkut Ata Üniversitesi, Mühendislik Fakültesi, Gıda Mühendisliği Bölümü, Osmaniye, Türkiye (ORCID: 0000-0002-4495-0206), \\ yasemincelebisezer@gmail.com
}

(İlk Geliş Tarihi 28 Eylül 2020 ve Kabul Tarihi 22 Şubat 2021)

(DOI: 10.31590 /ejosat.800887)

ATIF/REFERENCE: Çelebi Sezer, Y. (2021). Kayseri Piyasasında Satışa Sunulan Endüstriyel Tip Fermente, Kasap ve Isıl İşlem Görmüş Sucukların Biyojen Amin Miktarlarının Belirlenmesi. Avrupa Bilim ve Teknoloji Dergisi, (23), 43-51.

\section{$\ddot{O} \mathbf{z}$}

$\mathrm{Bu}$ çalışmada Kayseri piyasasında farklı üretim tekniği uygulanarak satışa sunulan sucukların kalitesi belirlenerek ürünlerin daha güvenilir bir şekilde tüketiminin sağlanabilmesi amacıyla biyojen amin içerik ve miktarları incelenmiştir. Bu amaçla 10 endüstriyel tip fermente sucuk (A), 10 1sıl işlem görmüş sucuk (B) ve 20 geleneksel yöntem ile üretilmiş kasap sucuğu (C) olmak üzere toplam da 40 adet örnek piyasadan rastgele temin edilmiş ve Yüksek Basınç Sıvı Kromotografisi (HPLC)'nde 254 nm dalga boyu, 40oC kolon sıcaklığı ve $1 \mathrm{ml} / \mathrm{dk}$ akış hızı koşullarında sekiz farklı biyojen amin konsantrasyonu (putresin, kadaverin, tiramin, histamin, triptamin, feniletilamin, spermin ve spermidin) incelenmiştir. Elde edilen sonuçlara göre kadaverin, putresin ve tiramin konsantrasyonları diğer biyojen aminlere kıyasla daha yüksek değerlere ulaşmıştır. C grup sucukların özellikle putresin, kadaverin ve tiramin miktarı A ve B grubu sucuklardan oldukça fazla miktarda $(\mathrm{P}<0.05)$ bulunmuştur. Putresin konsantrasyonu A grubu sucuklarda 14.61-132.26 mg/kg, B grubu sucuk örneklerinde 14.99-30.34 mg/kg aralıklarında gözlenirken, C grubu sucuklarda bu aralık belirgin bir şekilde artarak $24.46-542.35 \mathrm{mg} / \mathrm{kg}$ bulunmuştur. A ve B grubu sucuklarda tespit edilen ortalama tiramin değerleri sırasıyla $17.71 \mathrm{ve} 17.35 \mathrm{mg} / \mathrm{kg}$ bulunmakla birlikte C grubu sucuklarda bu değer bir hayli artarak $56.32 \mathrm{mg} / \mathrm{kg}$ 'a ulaştığı gözlenmiştir. A ve B grubu sucuk örneklerinde kadaverin tespit edilemezken, $\mathrm{C}$ grubu örneklerin yarısında tespit edilen kadaverinin ortalama değeri $106.61 \mathrm{mg} / \mathrm{kg}$ olarak bulunmuştur. Farklı üretim tekniği kullanılarak üretilen A, B ve C grubu sucukların histamin konsantrasyonlarında istatistiksel olarak önemli farklılıklar $(\mathrm{P}<0.05)$ tespit edilmiştir. A, B ve $\mathrm{C}$ grubu sucuklarda yaklaşı $\% 90$ oranında tespit edilen histamin sırasıyla $0-58.75 \mathrm{mg} / \mathrm{kg}$, $0-61.03$ ve $0-65.51 \mathrm{mg} / \mathrm{kg}$ aralıklarında bulunmuş ve sucuk grupları arasında önemli farkılıklar $(\mathrm{P}<0.05)$ gözlenmiştir. Küçük aminler olarak nitelendirilen triptamin ve feniletilaminin ortalama konsantrasyonları A, B ve C gruplarında sirasıly 9.77, 9.09, 13.04 mg/kg ve $2.80,2.12,6.06 \mathrm{mg} / \mathrm{kg}$ şeklinde $(\mathrm{P}<0.05)$ görülmüştür. Farklı üretim tekniği kullanılmasının spermin ve spermidin konsantrasyonlarını istatistiksel olarak etkilemediği $(\mathrm{P}>0.05)$ görülmüştür. Genel olarak, kasap sucuklarının (C), 1sıl işlem (B) ve endüstriyel tip fermente (A) sucuklardan biyojen amin miktarı açısından daha yüksek olduğu $(\mathrm{P}<0.05)$ tespit edilmiştir. Bu sonuçlara göre, starter kültür kullanılmadan gerçekleştirilen doğal fermantasyon işlemi sucuklarda yüksek oranda biyojen amin birikmesine neden olabilmektedir. Sonuç olarak, et ve et ürünlerinde istenmeyen mikrobiyal aktivitenin kalite indeksi ve göstergesi olarak kabul edilen biyojen amin konsantrasyonunun azaltılması için gelişmiş, hijyenik koşullar barındıran modern tesislerde üretimin gerçekleşmesi, negatif dekarboksilaz aktiviteye sahip starter kültürlerin kullanılması ve 1sıl işlem uygulaması ile biyojen aminlerin oluşumunun engellenmesi veya azaltılması mümkün olabilecektir.

Anahtar Kelimeler: Kasap sucuğu, Isıl işlem görmüş sucuk, Fermente sucuk, Biyojen amin.

\section{Determination of the Biogenic Amine Amounts of Industrial Type Fermented, Butcher's and Heat-Treated Sucuk Offered for Sale in Kayseri Market}

\begin{abstract}
In this study, the quality of sucuk sold for sale in Kayseri market by applying different production techniques was determined, and the content and amounts of biogenic amine were examined to ensure more reliable consumption of products. A total of 40 samples, including 10 industrial type fermented sucuk (A), 10 heat-treated sucuk (B), and 20 butcher's sucuk samples produced by the traditional method (C) were randomly obtained from the market, and eight different biogenic amine concentrations (putrescine, cadaverine, tyramine, histamine, tryptamine, phenylethylamine, spermine, and spermidine) were examined in High-Pressure Liquid Chromatography (HPLC) at a wavelength of $254 \mathrm{~nm}, 40 \mathrm{oC}$ column temperature, and $1 \mathrm{ml} / \mathrm{min}$ flow rate. According to the results cadaverine, putrescine, and tyramine concentrations reached higher values compared to other biogenic amines. It was found that especially the amounts of
\end{abstract}

* Sorumlu Yazar: yasemincelebisezer@gmail.com 
putrescine, cadaverine, and tyramine of group C sucuk were quite higher compared to groups A and B sucuk (P < 0.05). While the concentration of putrescine was observed to be in the range of 14.61-132.26 mg/kg in sucuk samples of group A and 14.99-30.34 mg/kg in sucuk samples of group B, this range increased significantly and was found to be $24.46-542.35 \mathrm{mg} / \mathrm{kg}$ in sucuk of group C. The mean values of tyramine were found to be 17.71 and $17.35 \mathrm{mg} / \mathrm{kg}$ in sucuk of groups A and B, respectively, it was observed that this value increased considerably and reached $56.32 \mathrm{mg} / \mathrm{kg}$ in sucuk of group C. While cadaverine was not detected in sucuk samples of groups $\mathrm{A}$ and $\mathrm{B}$, the mean value of cadaverine found in half of the group $\mathrm{C}$ samples was $106.61 \mathrm{mg} / \mathrm{kg}$. Statistically significant differences (P $<0.05)$ were found in the histamine concentrations of group A, B and C sucuk produced using different production techniques. Histamine detected at a rate of approximately $90 \%$ in group A, B, and C sucuk was found in the range of $0-58.75 \mathrm{mg} / \mathrm{kg}, 0-61.03$, and $0-65.51 \mathrm{mg} / \mathrm{kg}$, respectively, significant differences $(\mathrm{P}<0.05)$ were observed between sucuk groups. The mean concentrations of tryptamine and phenylethylamine, which are characterized as small amines, were observed to be $9.77,9.09,13.04 \mathrm{mg} / \mathrm{kg}$ and $2.80,2.12$, $6.06 \mathrm{mg} / \mathrm{kg}(\mathrm{P}<0.05)$ in groups A, B and C, respectively. It was observed that the use of different production techniques did not statistically affect the spermine and spermidine concentrations $(\mathrm{P}>0.05)$. In general, it was determined that butcher's sucuk $(\mathrm{C})$ had higher biogenic amine content compared to heat-treated $(\mathrm{B})$ and industrial-type fermented $(\mathrm{A})$ sucuk $(\mathrm{P}<0.05)$. According to these results, the natural fermentation process performed without the use of starter culture may cause a high accumulation of biogenic amine in sucuk. In conclusion, it will be possible to prevent or reduce the formation of biogenic amines by performing production in modern facilities with advanced and hygienic conditions, using starter cultures with negative decarboxylase activity and applying heat treatment in order to reduce the biogenic amine concentration, which is regarded as the quality index and indicator of undesirable microbial activity in meat and meat products.

Keywords: Butcher's sucuk, Heat-treated sucuk, Fermented sucuk, Biogenic amine.

\section{Giriş}

Sucuk, kıyılmış koyun veya sı̆̆ır eti, kuyruk yağı, tuz, şeker, kuru sarımsak, baharat ve bitkisel yağ ile karıştırılarak kılıflara doldurulan ve uygun koşullarda fermente edilen bir et ürünüdür (Bozkurt ve Erkmen, 2002; Kurt ve Zorba, 2010). Anadolu'da üretilen sucuklar, fermente ve 1 sıl işlem görmüşs sucuk (pastörize sucuk) olarak iki başlık altında gruplandırılmakla birlikte fermente sucuklar 1sıl işlem uygulanmaksızın doğal bir şekilde (kasap sucuğu) ya da sıcaklığı ve nemi ayarlanmış ortamda kurutulurak (endüstriyel fermente sucuk) üretilebilirler (Yıldırım, 1996; Kara ve Akkaya, 2010). Geleneksel metotlar ile üretilen ve standart üretim tekniği bulunmayan 1 sıl işlem görmemiş fermente sucuklarının bir çeşidi olan kasap sucukları küçük çaplı işletmelerde doğal ortamda kuru hava akımı uygulanarak üretilirler (Erkmen, 1999; Kara ve Akkaya, 2010). Bununla birlikte fabrikalarda ya da büyük ölçekli işletmelerde hijyenik kurallara uygun gelişmiş teknolojik imkanlara sahip starter kültür kullanılarak endüstriyel tip fermente sucuklar üretilebilir (Bozkurt ve Erkmen, 2002; Ensoy ve ark., 2010). Endüstriyel tip fermente sucuklarda kullanılan starter kültürler, fermantasyon süresini kontrollü bir şekilde hızlandırarak, belirli özelliklere sahip standart kalitede ve güvenilir fermente gıda üretmek amacıyla endüstride çokça kullanılan mikroorganizmalardır (Demirgül ve Sağdıç, 2017). Diğer taraftan sucuk üretimin akabinde 1sı işlemi uygulanan pastorize sucuklar, maliyet oranının daha düşük olması ve daha kısa süre de üretilmesi gibi nedenlerden dolayı endüstride tercih edilir duruma gelmiştir (Değirmencioğlu ve ark., 2006; Kara ve Akkaya, 2010).

Fermantasyon sırasında çeşitli fizikokimyasal ve mikrobiyal değişikliklerin meydana gelmesiyle üründe karakteristik renk, lezzet, tat ve doku değişimi meyadana gelmektedir (Papavergou, 2011). Fermantasyon sürecinde sucukta kullanılan etin yüksek oranda protein içeriği ve ette bulunan mikroorganizmaların dekarboksilaz aktivitesi biyojen amin oluşumunda önemli rol oynamaktadır. Biyojen aminler, biyolojik aktiviteye sahip düşük molekül ağırlıklı, 1sıya dayanıklı, uçucu olmayan, bazik azotlu bileşiklerin bir grubu olarak tanımlanır (Önal, 2007; Stadnik ve Dolatowski, 2010). Gida maddelerindeki amino asidin mikrobiyal dekarboksilasyonu veya amino asit transaminazları ile aldehitlerin ve ketonların aminasyonu ve transaminasyonu ile oluşmuştur (Kim ve ark., 2009; Stadnik ve Dolatowski, 2010; Ekici ve Omer, 2018). Bazı aminler nitrit ile reaksiyona girerek nitrosasyona tabi tutulabilir ve kanserojen olan ve insanlar için potansiyel bir sağlık tehdidi oluşturan uçucu nitrosaminler üretebilir (Önal, 2007; Ekici ve Omer, 2018). Sucuklardan izole edilen biyojen aminler, putresin, kadaverin, tiramin, histamin, triptamin, feniletilamin, ve doğal olarak oluşan poliaminlerden spermidin ve spermin'dir (Suzzi ve Gardini, 2003; Vidal-Carou ve ark., 2007; Papavergou, 2011). Histamin, tiramin, triptamin ve feniletilamin gibi biyojen aminler, sinir, mide ve vasküler sistemi etkilediği için bu maddeler açısından zengin gıdaların tüketimi gida kaynaklı hastalıklara neden olabilir (Papavergou, 2011). Ayrıca gıdalardaki histamin gibi biyojen aminlerin düzeylerinin belirlenmesi, bu ürünlerin tüketiminden kaynaklanan sağllk problemlerini değerlendirmek ve gida güvenliği ve kalitesi hakkında bilgi sahibi olabilmek açısından önem arz etmektedir (Bover-Cid ve ark., 1999; Ekici ve ark., 2004).

Biyojen aminlerin, sucuklarda risk faktörü oluşturmayacak seviyede bulunmasına yönelik ülkemizde belirli kural, kriter ve yasal düzenleme bulunmamasına rağmen, son yıllarda sucuklardaki biyojen amin miktarları ve bunların seviyelerini etkileyen faktörler incelenmeye başlanmıştır. Bu çalışmada, Türk et endüstrisinin en önemli şehirlerinden biri olan Kayseri'de (Kesmen ve ark., 2014) satışa sunulan sucuklarda biyojen amin varlığının gösterilmesi, oluşan biyojen amin miktarının belirlenmesi ve üretimsel farklılıkların biyojen amin oluşumuna ne derecede etki ettiğinin tespit edilmesi amaçlanmıştır. Böylece bu çalışma, tüketiciler için daha sağlıklı ve daha güvenilir sucukların üretilmesi konusunda yol gösterecektir.

\section{Materyal ve Metot}

\subsection{Materyal}

Kayseri piyasasında farklı üretim tekniği uygulanarak üretilmiş ve satışa sunulmuş (kasap sucuğu, endüstriyel tip fermente sucuk ve 1sıl ișlem görmüş sucuk) 2 paralel olarak düzenlenmiş 10 endüstriyel tip fermente, 20 kasap ve 101 ssll işlem görmüş sucuk örnekleri rastgele toplanmıştır. Endüstriyel tip fermente, 1sıl işlem görmüş ve kasap sucuklar sırasıyla A, B ve C şeklinde gruplandırılmıştır.

\subsubsection{Metod}

Örnek hazırlama ve biyojen amin analizi bazı modifikasyonlar yaparak Eerola ve ark. (1993)'e göre Yüksek 
Basınç Sıvı Kromotografisi (HPLC) yöntemi kullanılarak 2 paralel olarak gerçekleştirilmiştir.

\subsection{1. Örnek Hazırlanması ve Homojenizasyon}

Temiz bir paslanmaz çelik bıçakla dilimlenmiş $2 \mathrm{~g}$ sucuk örneği çok küçük parçalara ayrılmıştır. Üzerine $10 \mathrm{ml} 0.4 \mathrm{M}$ perklorik asit $\left(\mathrm{HClO}_{4}\right)$ ilave edilmiş UltraTurrax (Wisetis, Hg15d) ile homojenize edilerek süpernatant alınmıştır. Bu işlem bir kez daha tekrar edilmiş ve en son hacim perklorik asit ile $25 \mathrm{ml}$ 'ye tamamlanarak 3500 rpm'de 5 dakika boyunca santrifüj (Hettich, Mikro 220R) edilmiştir.

\subsection{2. Örneklerin Türevlendirilmesi ve Biyojen Amin} Analizi

Ekstraktların türevlendirme işleminin yapılması için $1 \mathrm{ml}$ ekstrakt üzerine $2 \mathrm{~N} 200 \mu \mathrm{l}$ sodyum hidroksit $(\mathrm{NaOH})$ ve $300 \mu \mathrm{l}$ aşırı doymuş sodyum bikarbonat $\left(\mathrm{NaHCO}_{3}\right)$ ilave edilmiş ve taze hazırlanan $2 \mathrm{ml}$ dansil klorit çözeltisi (10 mg DaCl/ $1 \mathrm{ml}$ aseton) ekstrakt üzerine eklenmiştir. Etüvde $45 \mathrm{dk} 40^{\circ} \mathrm{C}$ ' de bekletildikten sonra $100 \mu \mathrm{l} \% 25$ ' lik amonyak $\left(\mathrm{NH}_{3}\right)$ eklenmiş ve 30 dakika oda sıcaklığında bekletilmiştir. Asetonitril ilavesiyle hacim $5 \mathrm{ml}$ 'ye tamamlanarak $3500 \mathrm{rpm}$ 'de 5 dakika santrifüj edilmiş ve filtre edilerek $(0.45 \mu \mathrm{m})$ HPLC cihazına yerleştirilmiştir.

\subsubsection{HPLC Analizi}

Asetonitril (çözücü A) ve $0.4 \mathrm{M}$ amonyum format (çözücü B) mobil fazları ile gradyan elüsyon programı kullanılarak $\% 50$ çözücü A ve $\% 50$ çözücü B ile başlanmış $20 \mathrm{dk}$ içerisinde $\% 90$ çözücü A ve \%10 çözücü B değerlerine ulaşılarak ayırma işlemi 37. dk'da bitirilmiştir. Akış hızı $1 \mathrm{ml} / \mathrm{dk}$ ve kolon sıcaklığ $40^{\circ} \mathrm{C}$ olarak uygulanmıştır. Biyojen aminler $254 \mathrm{~nm}$ dalga boyunda analiz edilmiştir. Amin analizi için Anionex Ultimate 3000 diode array dedektör, iki kanallı gradient pompa (Ultimate, 3000 Pump), kolon firını (Ultimate 3000), autosampler (Ultimate 3000) Choromomelon package programina sahip Thermo Scientific Dionex Ultimate HPLC ve Spherisorb ODS2, $10 \mu \mathrm{m}, 200 x 4.60$ mm, kolon (Phenomenex, Torrance, CA, US) kullanılmıştır.

\section{3. İstatiksel Analiz}

HPLC analizi ile elde edilen veriler SPSS paket programı (SPSS, 18.0) kullanılarak aynı üretim tekniğine sahip sucukların biyojen amin miktarları ve farklı üretim yöntemlerinin kendi aralarındaki biyojen amin oluşumuna etkileri One-way Anova (Duncan) testi ile 0.05 önemlilik derecesine göre istatistiki olarak karşılaştırılmıştır.

\section{Araştırma Sonuçları ve Tartışma}

Çalışmada Kayseri piyasasından temin edilen üç farklı üretim şartlarında (endüstriyel tip fermente, isıl işlem görmüş ve geleneksel tip fermente kasap sucuğu) üretilen toplamda 40 sucuk örneğinde sekiz farklı biyojen amin konsantrasyonu (putresin, kadaverin, tiramin, histamin, triptamin, feniletilamin, spermin ve spermidin) belirlenmiştir. Sucukların biyojen amin miktarları istatiksel farkl1lıklarıyla Tablo 1'de, ortalama biyojen amin miktarları Şekil 1'de ve farklı üretim teknolojisinin biyojen amin konsantrasyonu üzerine etkisini gösteren istatistiksel analiz sonuçları da Tablo 2'de verilmiştir.

Farklı işleme koşulları nedeniyle gruplar arasında bazı biyojen amin konsantrasyonlarında önemli farklılıklar bulunmuştur. Bununla birlikte, aynı grupta bulunan örnekler arasında da özellikle putresin, kadaverin, histamin ve tiramin konsantrasyonlarında belirgin farklılıklar saptanmıştır. Bu sonuç, ham maddenin hijyenik kalitesinin, sucuk üretimi sırasında biyojen amin formülasyonu üzerindeki önemini doğrulamaktadır (Sivamaruthi ve ark.., 2020). Çok sayıda yazar tarafından ham madde kalitesinin biyojen amin oluşumu üzerinde etkili olduğu vurgulanmıştır (Doeun ve ark., 2017; Sivamaruthi ve ark.., 2020). Geleneksel olarak Çin'de üretilen tütsülenmiş at eti sucuklarında feniletilamin, kadaverin, histamin, spermidin ve spermin miktarları sirasiyla $60.96 \mathrm{mg} / \mathrm{kg}, 24.54-178.03 \mathrm{mg} / \mathrm{kg}, 90.56$ $\mathrm{mg} / \mathrm{kg}, 22.03 \mathrm{mg} / \mathrm{kg}$ ve $7.12 \mathrm{mg} / \mathrm{kg}$ şeklinde rapor edilmiştir ( $\mathrm{Lu}$ ve ark., 2015). Blagojevic ve ark. (2015) putresin, kadaverin ve tiramin miktarlarını fermente sosislerde sirasıyla $50.9 \mathrm{mg} / \mathrm{kg}, 33$ $\mathrm{mg} / \mathrm{kg}$ ve $24.8 \mathrm{mg} / \mathrm{kg}$, Domínguez ve ark. (2016) putresin, histamin, spermidin ve spermin miktarlarını sırasıyla $3.27 \mathrm{mg} / \mathrm{kg}$, $4.12 \mathrm{mg} / \mathrm{kg}, 11.75 \mathrm{mg} / \mathrm{kg}$ ve $24.1 \mathrm{mg} / \mathrm{kg}$ şeklinde bildirmişlerdir. Fermente edilmiş sucuklarda histamin miktarını Erkmen ve Bozkurt (2004) 1.8-478.2 mg/kg, Coloretti ve ark. (2014) 0- 94.78 $\mathrm{mg} / \mathrm{kg}$ ve Stojanović ve Svarc-Gajic (2011) 39.91-196.86 mg/kg aralığında tespit etmişlerdir. Bununla birlikte ham maddenin hiyyenik kalitesinin yanında, $\mathrm{pH}$, su aktivitesi, sıcaklık, redoks potansiyeli, oksijen kaynağı, gıdanın doğası, koruyucular, $\mathrm{NaCl}$ ve katkı maddeleri gibi değişkenler de sucuklarda biyojen amin oluşumu üzerinde önemli bir etkiye sahip olabilmektedir (Suzzi ve Gardini, 2003; Ekici ve Omer, 2018).

Et ve et ürünlerinde biyojen amin oluşumu temelde dekarboksilaz enzimleri aracılığıyla serbest amino asitlerin dekarboksilasyonu ile gerçekleşmektedir. Biyojen amin konsantrasyonu, et ve et ürünlerinde istenmeyen mikrobiyal aktivitenin kalite indeksi ve göstergesi olarak kullanılmaktadır (Doeun ve ark. 2017). Tablo 2'de de görüldüğü gibi A, B ve C gruplarının biyojen aminlerin içeriklerinde önemli istatistiksel olarak önemli farklılıklar $(\mathrm{P}<0.05)$ bulunmuştur. Elde edilen sonuçlara göre genel olarak $\mathrm{C}$ grup geleneksel yöntem ile üretilen kasap sucuklarının toplam biyojen amin miktarının $(\mathrm{P}<0.05)$ daha yüksek olduğu gözlenmiştir (Tablo 2, Şekil 1). Özellikle putresin, kadaverin ve tiramin miktarının A ve B grubu sucuklardan oldukça fazla miktarda $(\mathrm{P}<0.05)$ olduğu tespit edilmiştir (Tablo 2). Putresin konsantrasyonu A grubu endüstriyel tip fermente sucuklarında 14.61-132.26 mg/kg, B grubu 1sıl işlem sucuk örneklerinde 14.99-30.34 mg/kg aralıklarında gözlenirken, C grubu kasap sucuğunda 24.46-542.35 mg/kg aralığında gözlenmiştir (Tablo 1). Fermente sucuk ile ilgili daha önce yapılan çalışmalarda benzer bir şekilde, putresin konsantrasyonu $0-412 \mathrm{mg} / \mathrm{kg}$ ve $0-255.625 \mathrm{mg} / \mathrm{kg}$ aralıklarında rapor edilmiştir (Ayhan ve ark. 1999; Ekici ve Omer, 2018). A ve B grubu sucuklarda ortalama putresin konsantrasyonu sirasiyla 15.30 $\mathrm{mg} / \mathrm{kg}$ ve $22.29 \mathrm{mg} / \mathrm{kg}$ gözlenirken, C grubu sucuklarda bu değer bir hayli artarak $155.05 \mathrm{mg} / \mathrm{kg}$ 'a kadar ulaşmıştır (Şekil 1). A ve B grubu sucuk örneklerinde kadaverin tespit edilemezken, C grup sucuk örneklerinin yarısında kadaverin tespit edilmiştir (Tablo 1, Şekil 1). C grubu sucuklarda ortalama kadaverin değeri 106.61 $\mathrm{mg} / \mathrm{kg}$ olarak gözlenmiştir (Tablo 2). Elde edilen sonuçlara paralel olarak Erkmen ve Bozkurt (2004)'in yaptığı çalışmada kasap sucuklarının \%22.6'sında kadaverin tespit edilmişken, fabrika sucuklarında kadaverin bulunmadığı bildirilmiştir. Tiramin özellikle monoamin oksidaz inhibitörleri (MAOI) içeren antidepresan ilaçlar ile birlikte kullanıldığında kan basıncı artışına neden olabilmektedir (Latorre-Moratalla ve ark. 2017). Bununla birlikte izin verilen maksimum tiramin seviyesi $800 \mathrm{mg} / \mathrm{kg}$ olarak bildirilmiştir (Shalaby, 1996; Latorre-Moratalla ve ark. 2017). Çalışmada test edilen tüm sucukların tiramin konsantrasyonları 10.79- $121.88 \mathrm{mg} / \mathrm{kg}$ arasında değişmekte ve Shalaby 1996'a göre kabul edilebilir düzeyde tespit edilmiştir (Tablo 1). Aynı zamanda 
Şekil 1'de görüldüğü gibi A ve B tipi sucuklarda tespit edilen ortalama tiramin değerleri $17.71 \mathrm{mg} / \mathrm{kg}$ ve $17.35 \mathrm{mg} / \mathrm{kg}$ gözlenmesine rağmen $\mathrm{C}$ grubu sucuklarda bu değer bir hayli artarak $56.32 \mathrm{mg} / \mathrm{kg}$ 'a ulaşmıştır. Farklı üretim tekniği kullanılarak üretilen sucukların histamin konsantrasyonlarında istatistiksel olarak önemli farklılıklar $(\mathrm{P} \quad<0.05)$ bulunabilmektedir.

Tablo 1. Sucukların Biyojen Amin Miktarları

\begin{tabular}{|c|c|c|c|c|c|c|c|c|}
\hline \multirow{2}{*}{$\begin{array}{c}\text { Sucuk } \\
\text { Grupları }\end{array}$} & \multicolumn{8}{|c|}{ Biyojen Amin Miktarları (mg /kg) } \\
\hline & Putresin & Kadaverin & Histamin & Tiramin & Triptamin & Feniletilamin & Spermin & Spermidin \\
\hline 1 & $16.52 \pm 0.40^{\mathrm{c}}$ & t.e. & $55.00 \pm 1.35^{\mathrm{c}}$ & $11.67 \pm 0.28^{\text {e.f }}$ & $9.26 \pm 0.14 \mathrm{~d}$ & $2.29 \pm 0.03^{\mathrm{e}, \mathrm{f}}$ & $24.09 \pm 0.59^{c}$ & $36.85 \pm 0.58^{\mathrm{b}, \mathrm{c}}$ \\
\hline 2 & $14.61 \pm 0.35^{\mathrm{c}}$ & t.e. & $0.48 \pm 0.015^{\mathrm{f}}$ & $10.79 \pm 0.26^{\mathrm{f}}$ & $10.3 \pm 0.16^{\mathrm{a}}$ & $3.39 \pm 0.05^{\mathrm{b}}$ & $22.00 \pm 0.54^{\mathrm{d}}$ & $37.95 \pm 0.60^{\mathrm{a}, \mathrm{b}, \mathrm{c}}$ \\
\hline 3 & $132.26 \pm 3.25^{\mathrm{a}}$ & t.e. & $0.65 \pm 0.01^{\mathrm{f}}$ & $37.00 \pm 0.90^{\mathrm{a}}$ & $9.98 \pm 0.15^{\mathrm{b}, \mathrm{c}}$ & $3.01 \pm 0.08^{c}$ & $21.99 \pm 0.55^{\mathrm{d}}$ & $37.57 \pm 0.59^{\mathrm{a}, \mathrm{b}, \mathrm{c}}$ \\
\hline 4 & $122.37 \pm 3.00^{\mathrm{b}}$ & t.e. & $55.99 \pm 1.37^{\text {b.c }}$ & $30.58 \pm 0.75^{\mathrm{b}}$ & $9.19 \pm 0.14^{\mathrm{d}}$ & $2.22 \pm 0.04^{\mathrm{f}}$ & $21.96 \pm 0.53^{\mathrm{d}}$ & $36.78 \pm 0.60^{b, c}$ \\
\hline 5 & $16.99 \pm 0.45^{\mathrm{c}}$ & t.e. & $5.24 \pm 0.13^{\mathrm{e}}$ & $11.43 \pm 0.28^{\text {e.f }}$ & $10.00 \pm 0.15^{\mathrm{b}, \mathrm{c}}$ & $3.02 \pm 0.06^{\mathrm{c}}$ & $33.78 \pm 0.83^{\mathrm{a}}$ & $38.43 \pm 0.65^{\mathrm{a}}$ \\
\hline 6 & $17.68 \pm 0.43^{\mathrm{c}}$ & t.e. & $57.18 \pm 1.40^{\mathrm{b}}$ & $11.22 \pm 0.27^{\mathrm{f}}$ & $10.50 \pm 0.16^{\mathrm{a}}$ & $3.53 \pm 0.06^{\mathrm{a}}$ & $32.72 \pm 0.80^{\mathrm{a}}$ & $38.09 \pm 0.63^{\mathrm{a}, \mathrm{b}}$ \\
\hline 7 & $17.62 \pm 0.43^{\mathrm{c}}$ & t.e. & $0.18 \pm 0.00^{\mathrm{f}}$ & $12.49 \pm 0.30^{\mathrm{e}}$ & $10.27 \pm 0.16^{\mathrm{a}, \mathrm{b}}$ & $3.30 \pm 0.07^{b}$ & $27.86 \pm 0.68^{b}$ & $37.86 \pm 0.66^{\mathrm{a}, \mathrm{b}, \mathrm{c}}$ \\
\hline 8 & $16.61 \pm 0.40^{\mathrm{c}}$ & t.e. & $61.03 \pm 1.49^{\mathrm{a}}$ & $15.01 \pm 0.36^{\mathrm{d}}$ & $9.78 \pm 0.15^{\mathrm{c}}$ & $2.81 \pm 0.05^{\mathrm{d}}$ & $21.95 \pm 0.54^{\mathrm{d}}$ & $37.28 \pm 0.34^{\mathrm{a}, \mathrm{b}, \mathrm{c}}$ \\
\hline 9 & $17.95 \pm 0.52^{\mathrm{c}}$ & t.e. & $28.82 \pm 0.70^{\mathrm{d}}$ & $14.70 \pm 0.36^{\mathrm{d}}$ & $8.99 \pm 0.14^{\mathrm{d}}$ & $2.02 \pm 0.03^{\mathrm{g}}$ & $24.01 \pm 0.59^{c}$ & $36.57 \pm 0.88^{\mathrm{b}, \mathrm{c}}$ \\
\hline 10 & $15.30 \pm 0.37^{\mathrm{c}}$ & t.e. & t.e. & $22.23 \pm 0.54^{\mathrm{c}}$ & $9.36 \pm 0.13^{\mathrm{d}}$ & $2.39 \pm 0.04^{\mathrm{e}}$ & $24.28 \pm 0.59^{\mathrm{c}}$ & $36.94 \pm 0.68^{b, c}$ \\
\hline 1 & $28.36 \pm 0.75^{\mathrm{b}}$ & t.e. & $58.49 \pm 0.8$ & $18.68 \pm 0.16^{\mathrm{c}}$ & $11.01 \pm 0.23^{\mathrm{a}}$ & $4.04 \pm 0.16^{\mathrm{a}}$ & $23.08 \pm 0.02^{\mathrm{f}}$ & $38.6 \pm 0.61^{\mathrm{a}}$ \\
\hline 2 & $18.41 \pm 0.48^{\mathrm{f}}$ & t.e. & $3.11 \pm 0.04^{\mathrm{e}}$ & $15.76 \pm 0.14^{\mathrm{f}}$ & $9.88 \pm 0.25^{\mathrm{c}}$ & $2.91 \pm 0.04^{\mathrm{c}}$ & $22.85 \pm 0.02^{\mathrm{g}}$ & $37.47 \pm 0.89^{\mathrm{a}, \mathrm{b}, \mathrm{c}, \mathrm{d}, \mathrm{e}}$ \\
\hline 3 & $26.28 \pm 0.69^{c}$ & t.e. & $58.75 \pm 0.90^{\mathrm{a}}$ & $17.53 \pm 0.15^{\mathrm{d}}$ & $7.09 \pm 0.12^{\mathrm{g}}$ & $0.12 \pm 0.03^{\mathrm{h}}$ & $31.93 \pm 0.03^{\mathrm{a}}$ & $38.43 \pm 0.81^{\mathrm{a}, \mathrm{b}}$ \\
\hline 4 & $21.78 \pm 0.57^{\mathrm{d}}$ & t.e. & $2.61 \pm 0.04^{\mathrm{e}}$ & $14.97 \pm 0.13^{\mathrm{h}}$ & $9.51 \pm 0.25^{\mathrm{d}}$ & $2.54 \pm 0.04^{\mathrm{d}}$ & $26.79 \pm 0.02^{\mathrm{c}}$ & $37.1 \pm 0.88 b^{, c, d, e}$ \\
\hline 5 & $16.45 \pm 0.43^{\mathrm{g}}$ & t.e. & t.e. & $15.39 \pm 0.13^{\mathrm{g}}$ & $9.25 \pm 0.15 \mathrm{~d}^{\mathrm{e}}$ & $2.28 \pm 0.03^{\mathrm{e}}$ & $25.19 \pm 0.02^{\mathrm{e}}$ & $36.84 \pm 0.88^{\mathrm{c}, \mathrm{d}, \mathrm{e}}$ \\
\hline 6 & $14.99 \pm 0.39^{\mathrm{h}}$ & t.e. & $18.73 \pm 0.28^{\mathrm{d}}$ & $18.89 \pm 0.16^{\mathrm{c}}$ & $0.93 \pm 0.15$ & $1.96 \pm 0.03^{\mathrm{f}}$ & $25.56 \pm 0.023^{\mathrm{d}}$ & $36.52 \pm 0.77^{\mathrm{d}, \mathrm{e}}$ \\
\hline 7 & $30.34 \pm 0.45^{\mathrm{a}}$ & t.e. & $35.21 \pm 0.54^{\mathrm{c}}$ & $15.17 \pm 0.13^{\mathrm{g} . \mathrm{h}}$ & $6.98 \pm 0.11^{\mathrm{g}}$ & $0.012 \pm 0.00^{1}$ & $22.68 \pm 0.02^{\mathrm{h}}$ & $37.68 \pm 0.69^{\mathrm{a}, \mathrm{b}, \mathrm{c}, \mathrm{d}}$ \\
\hline 8 & $25.30 \pm 0.66^{\mathrm{c}}$ & t.e. & $3.68 \pm 0.05^{\mathrm{e}}$ & $16.72 \pm 0.14^{\mathrm{e}}$ & $10.61 \pm 0.17^{b}$ & $3.64 \pm 0.06^{\mathrm{b}}$ & $31.57 \pm 0.02^{\mathrm{b}}$ & $38.2 \pm 0.60^{\mathrm{a}, \mathrm{b}, \mathrm{c}}$ \\
\hline 9 & $20.27 \pm 0.53^{\mathrm{e}}$ & t.e. & $54.08 \pm 0.83^{\mathrm{a}}$ & $20.79 \pm 0.18^{\mathrm{a}}$ & $9.18 \pm 0.15^{\mathrm{d}, \mathrm{e}}$ & $2.20 \pm 0.03^{\mathrm{e}}$ & $22.40 \pm 0.02^{1}$ & $37.67 \pm 0.69^{a, b, c, d}$ \\
\hline 10 & $20.76 \pm 0.53^{\text {d.e }}$ & t.e. & t.e. & $19.60 \pm 0.17^{\mathrm{b}}$ & $8.47 \pm 0.23^{\mathrm{f}}$ & $1.50 \pm 0.02^{\mathrm{g}}$ & $22.38 \pm 0.02^{1}$ & $36.05 \pm 0.67^{\mathrm{e}}$ \\
\hline 1 & $55.74 \pm 1.39^{\mathrm{k}}$ & $212.24 \pm 3.56^{\mathrm{c}}$ & $9.19 \pm 0.07^{\mathrm{f}}$ & $77.32 \pm 1.79^{\mathrm{f}}$ & $12.41 \pm 0.20^{\mathrm{h}}$ & $5.43 \pm 0.08^{\mathrm{h}}$ & $29.44 \pm 0.93^{\mathrm{g}}$ & $39.99 \pm 0.63^{\mathrm{d}, \mathrm{e}, \mathrm{f}, \mathrm{g}}$ \\
\hline 2 & $48.68 \pm 1.21^{\mathrm{k}}$ & $177.12 \pm 2.97^{\mathrm{d}}$ & $37.45 \pm 0.30^{\mathrm{e}}$ & $79.41 \pm 1.84^{\mathrm{e}}$ & $11.44 \pm 1.18^{\mathrm{k}, 1}$ & $4.46 \pm 0.07^{\mathrm{j}}$ & $21.85 \pm 0.69^{1}$ & $39.0 \pm 0.81^{\mathrm{f}, \mathrm{g}, \mathrm{h}}$ \\
\hline 3 & $28.90 \pm 0.72^{1}$ & $137.94 \pm 2.32^{\mathrm{f}}$ & $56.55 \pm 0.46^{\mathrm{c}}$ & $76.67 \pm 1.77^{\mathrm{f}}$ & $14.89 \pm 0.84^{b}$ & $7.91 \pm 0.12^{\mathrm{b}}$ & $21.85 \pm 0.69^{1}$ & $42.47 \pm 0.87^{\mathrm{b}}$ \\
\hline 4 & $30.38 \pm 0.76^{1}$ & $170.75 \pm 2.87^{\mathrm{e}}$ & $5.83 \pm 0.05^{\mathrm{g} . \mathrm{h}}$ & $96.33 \pm 2.23^{\mathrm{b}}$ & $12.97 \pm 0.61^{\mathrm{e}, \mathrm{f}, \mathrm{g}}$ & $5.99 \pm 0.09^{\mathrm{f}, \mathrm{g}}$ & $41.61 \pm 1.31^{\mathrm{a}}$ & $40.54 \pm 0.84^{\mathrm{c}, \mathrm{d}, \mathrm{e}, \mathrm{f}}$ \\
\hline 5 & $267.21 \pm 6.65^{\mathrm{d}}$ & $476.47 \pm 8^{\mathrm{a}}$ & $43.97 \pm 0.36^{\mathrm{d}}$ & $121.88 \pm 2.82^{\mathrm{a}}$ & $11.16 \pm 0.88^{1, \mathrm{~m}}$ & $4.19 \pm 0.07^{\mathrm{k}}$ & $34.87 \pm 1.10^{\mathrm{b}}$ & $38.74 \pm 0.81^{\mathrm{g}, \mathrm{h}}$ \\
\hline 6 & $184.33 \pm 4.59^{\text {e.f }}$ & $285.42 \pm 4.79^{b}$ & t.e. & $85.40 \pm 1.97^{\mathrm{c}}$ & $13.98 \pm 0.42^{\mathrm{c}, \mathrm{d}}$ & $7.00 \pm 0.11^{\mathrm{d}}$ & $21.88 \pm 0.69^{1}$ & $40.55 \pm 0.84^{\mathrm{c}, \mathrm{d}, \mathrm{e}, \mathrm{f}}$ \\
\hline 7 & $60.78 \pm 1.51^{\mathrm{k}}$ & t.e. & $3.47 \pm 0.03^{1}$ & $61.38 \pm 1.42^{\mathrm{h}}$ & $13.17 \pm 0.31^{\mathrm{e}, \mathrm{f}}$ & $6.20 \pm 0.09^{f}$ & $34.17 \pm 1.08^{c}$ & $40.75 \pm 0.86^{\mathrm{c}, \mathrm{d}, \mathrm{e}}$ \\
\hline 8 & $58.66 \pm 1.46^{\mathrm{k}}$ & t.e. & $41.80 \pm 0.34^{\mathrm{d}}$ & $64.16 \pm 1.48^{\mathrm{g}}$ & $12.57 \pm 0.30^{\mathrm{g}}$ & $5.59 \pm 0.09^{\mathrm{h}}$ & $21.95 \pm 0.69^{1}$ & $40.15 \pm 0.83^{\mathrm{d}, \mathrm{e}, \mathrm{f}, \mathrm{g}}$ \\
\hline 9 & $24.46 \pm 0.61^{1}$ & te & $62.04 \pm 0.50^{\mathrm{b}}$ & $16.15 \pm 0.37^{1}$ & $9.74 \pm 0.25^{\mathrm{n}}$ & $2.76 \pm 0.05^{\mathrm{m}}$ & $22.23 \pm 0.70^{1}$ & $37.32 \pm 0.79^{1}$ \\
\hline 10 & $26.01 \pm 0.65^{1}$ & to & $5.17 \pm 0.04^{\mathrm{g} . \mathrm{h}}$ & $15.96 \pm 0.37^{1}$ & $10.82 \pm 0.27^{\mathrm{m}}$ & $3.85 \pm 0.07^{1}$ & $22.24 \pm 0.70^{1}$ & $38.40 \pm 0.80^{\mathrm{h}, 1}$ \\
\hline 11 & $189.33 \pm 4.71^{\mathrm{e}}$ & t.e. & $6.59 \pm 0.05^{\mathrm{g}}$ & $19.63 \pm 0.45^{\mathrm{k}}$ & $14.95 \pm 0.34^{\mathrm{b}}$ & $7.97 \pm 0.14^{b}$ & $23.51 \pm 0.74^{\mathrm{h}}$ & $42.53 \pm 0.87^{b}$ \\
\hline 12 & $143.47 \pm 3.57^{\mathrm{g}}$ & t.e. & $60.09 \pm 0.49^{\mathrm{b}}$ & $17.13 \pm 0.40^{1}$ & $13.54 \pm 0.32^{\mathrm{d}, \mathrm{e}}$ & $6.57 \pm 0.16^{\mathrm{e}}$ & $22.84 \pm 0.72^{1}$ & $41.12 \pm 0.83^{\mathrm{b}, \mathrm{c}, \mathrm{d}}$ \\
\hline 13 & $125.41 \pm 3.12^{\mathrm{h}}$ & $62.11 \pm 1.04^{\mathrm{h}}$ & $4.35 \pm 0.04^{\mathrm{g} . \mathrm{h}}$ & $82.85 \pm 1.92^{\mathrm{d}}$ & $11.87 \pm 0.46^{\mathrm{j}, \mathrm{k}}$ & $4.90 \pm 0.08^{1}$ & $21.85 \pm 0.69^{1}$ & $39.45 \pm 0.82^{\mathrm{e}, \mathrm{f}, \mathrm{g}, \mathrm{h}}$ \\
\hline 14 & $173.32 \pm 4.31^{\mathrm{f}}$ & $112.83 \pm 1.89^{\mathrm{g}}$ & $55.39 \pm 0.45^{\mathrm{c}}$ & $95.05 \pm 2.20^{\mathrm{b}}$ & $17.98 \pm 0.39^{\mathrm{a}}$ & $11.00 \pm 0.18^{\mathrm{a}}$ & $21.86 \pm 0.69^{1}$ & $44.70 \pm 0.91^{\mathrm{a}}$ \\
\hline
\end{tabular}


European Journal of Science and Technology

Tablo 1. (Devamı) Sucukların Biyojen Amin Miktarları

\begin{tabular}{ccccccccc} 
& \multicolumn{7}{c}{ Biyojen Amin Miktarları (mg /kg) } \\
\cline { 2 - 8 } Sucuk Grupları & Putresin & Kadaverin & Histamin & Tiramin & Triptamin & Feniletilamin & Spermin & Spermidin \\
\hline 15 & $98.28 \pm 2.45^{1}$ & t.e. & $61.16 \pm 0.49^{\mathrm{b}}$ & $13.75 \pm 0.32^{\mathrm{m}}$ & $14.24 \pm 0.43^{\mathrm{c}}$ & $7.26 \pm 0.14^{\mathrm{c}}$ & $33.00 \pm 1.04^{\mathrm{d}}$ & $41.82 \pm 0.86^{\mathrm{b}, \mathrm{c}}$ \\
16 & $51.62 \pm 1.28^{\mathrm{k}}$ & t.e. & $1.70 \pm 0.01^{1 . \mathrm{j}}$ & $12.61 \pm 0.29^{\mathrm{m} . \mathrm{n}}$ & $11.97 \pm 0.39^{1}$ & $4.99 \pm 0.09^{1}$ & $22.31 \pm 0.70^{\mathrm{j} \cdot \mathrm{k}}$ & $39.55 \pm 0.72^{\mathrm{e}, \mathrm{f}, \mathrm{g}, \mathrm{h}}$ \\
17 & $295.66 \pm 7.36^{\mathrm{c}}$ & t.e. & $6.50 \pm 0.05^{\mathrm{g}}$ & $45.49 \pm 1.05^{\mathrm{j}}$ & $12.81 \pm 0.30^{\mathrm{f}, \mathrm{g}}$ & $5.83 \pm 0.12^{\mathrm{g}}$ & $22.39 \pm 0.80^{\mathrm{j} \cdot \mathrm{k}}$ & $40.39 \pm 0.83^{\mathrm{c}, \mathrm{d}, \mathrm{e}, \mathrm{f}}$ \\
18 & $295.58 \pm 7.36^{\mathrm{c}}$ & t.e. & $65.51 \pm 0.53^{\mathrm{a}}$ & $47.74 \pm 1.10^{1}$ & $11.80 \pm 0 . .^{39 j, \mathrm{k}}$ & $4.83 \pm 0.08^{1}$ & $22.43 \pm 0.71^{\mathrm{j}}$ & $39.38 \pm 0.85^{\mathrm{e}, \mathrm{f}, \mathrm{g}, \mathrm{h}}$ \\
19 & $400.80 \pm 9.97^{\mathrm{b}}$ & $212.23 \pm 3.56^{\mathrm{c}}$ & $35.52 \pm 0.29^{\mathrm{e}}$ & $86.31 \pm 2.00^{\mathrm{c}}$ & $13.63 \pm 0.87^{\mathrm{d}, \mathrm{e}}$ & $6.65 \pm 0.21^{\mathrm{e}}$ & $30.18 \pm 0.95^{\mathrm{f}}$ & $41.21 \pm 0.75^{\mathrm{b}, \mathrm{c}, \mathrm{d}}$ \\
20 & $542.35 \pm 13.50^{\mathrm{a}}$ & $285.18 \pm 4.79^{\mathrm{b}}$ & t.e. & $11.22 \pm 0.26^{\mathrm{n}}$ & $14.89 \pm 0.44^{\mathrm{b}}$ & $7.91 \pm 0.22^{\mathrm{b}}$ & $31.42 \pm 0.99^{\mathrm{e}}$ & $40.53 \pm 0.74^{\mathrm{c}, \mathrm{d}, \mathrm{e}, \mathrm{f}}$
\end{tabular}

* ortalama değerler \pm standart sapmaları. Farklı harfler istatistiksel olarak birbirinden farklı olduğu anlamına gelir $(\mathrm{P}<0.05)$. Aynı grup içerisindeki sucukların istatistiki farklılıkları belirlenmiştir. t.e. : tespit edilemedi.

Tablo 2. Farklı Üretim Tekniğine Sahip Sucuk Gruplarının Biyojen Amin Konsantrasyonlarının İstatiksel Farklılıkları

\begin{tabular}{|c|c|c|}
\hline Biyojen Amin & Üretim Yöntemi & Ortalama \\
\hline \multirow{3}{*}{ Putresin } & (A) & $15.30 \pm 0.69^{b}$ \\
\hline & (B) & $22.29 \pm 1.01^{\mathrm{b}}$ \\
\hline & (C) & $155.05 \pm 7.00^{\mathrm{a}}$ \\
\hline \multirow{3}{*}{ Kadaverin } & (A) & t.e. \\
\hline & (B) & t.e. \\
\hline & (C) & $106.61 \pm 1.70^{\mathrm{a}}$ \\
\hline \multirow{3}{*}{ Histamin } & (A) & $26.20 \pm 0.46^{\mathrm{b}}$ \\
\hline & (B) & $23.05 \pm 0.40^{c}$ \\
\hline & (C) & $28.02 \pm 0.49^{a}$ \\
\hline \multirow{3}{*}{ Tiramin } & (A) & $17.71 \pm 0.31^{\mathrm{b}}$ \\
\hline & (B) & $17.35 \pm 0.30^{\mathrm{b}}$ \\
\hline & (C) & $56.32 \pm 0.98^{\mathrm{a}}$ \\
\hline \multirow{3}{*}{ Triptamin } & (A) & $9.77 \pm 0.18^{b}$ \\
\hline & (B) & $9.09 \pm 0.20^{c}$ \\
\hline & $(\mathrm{C})$ & $13.04 \pm 0.34^{\mathrm{a}}$ \\
\hline \multirow{3}{*}{ Feniletilamin } & (A) & $2.80 \pm 0.005^{\mathrm{b}}$ \\
\hline & (B) & $2.12 \pm 0.004^{\mathrm{c}}$ \\
\hline & $(\mathrm{C})$ & $6.06 \pm 0.02^{\mathrm{a}}$ \\
\hline \multirow{3}{*}{ Spermin } & (A) & $25.46 \pm 0.44^{\mathrm{a}}$ \\
\hline & (B) & $25.44 \pm 0.44^{\mathrm{a}}$ \\
\hline & (C) & $26.19 \pm 0.46^{\mathrm{a}}$ \\
\hline \multirow{3}{*}{ Spermidin } & (A) & $37.43 \pm 1.29^{a}$ \\
\hline & (B) & $37.45 \pm 1.31^{\mathrm{a}}$ \\
\hline & (C) & $40.43 \pm 1.45^{\mathrm{a}}$ \\
\hline \multirow{3}{*}{ Toplam Biyojen Amin } & (A) & $134.69 \pm 4.38^{\mathrm{b}}$ \\
\hline & (B) & $136.83 \pm 5.54^{b}$ \\
\hline & (C) & $422.34 \pm 13.40^{\mathrm{a}}$ \\
\hline
\end{tabular}

* ortalama değerler \pm standart sapmaları. Farklı harfler istatistiksel olarak birbirinden farklı olduğu anlamına gelir $(\mathrm{P}<0.05)$. Üretim yöntemine göre farklılıklar değerlendirilmiştir. t.e. : tespit edilemedi 


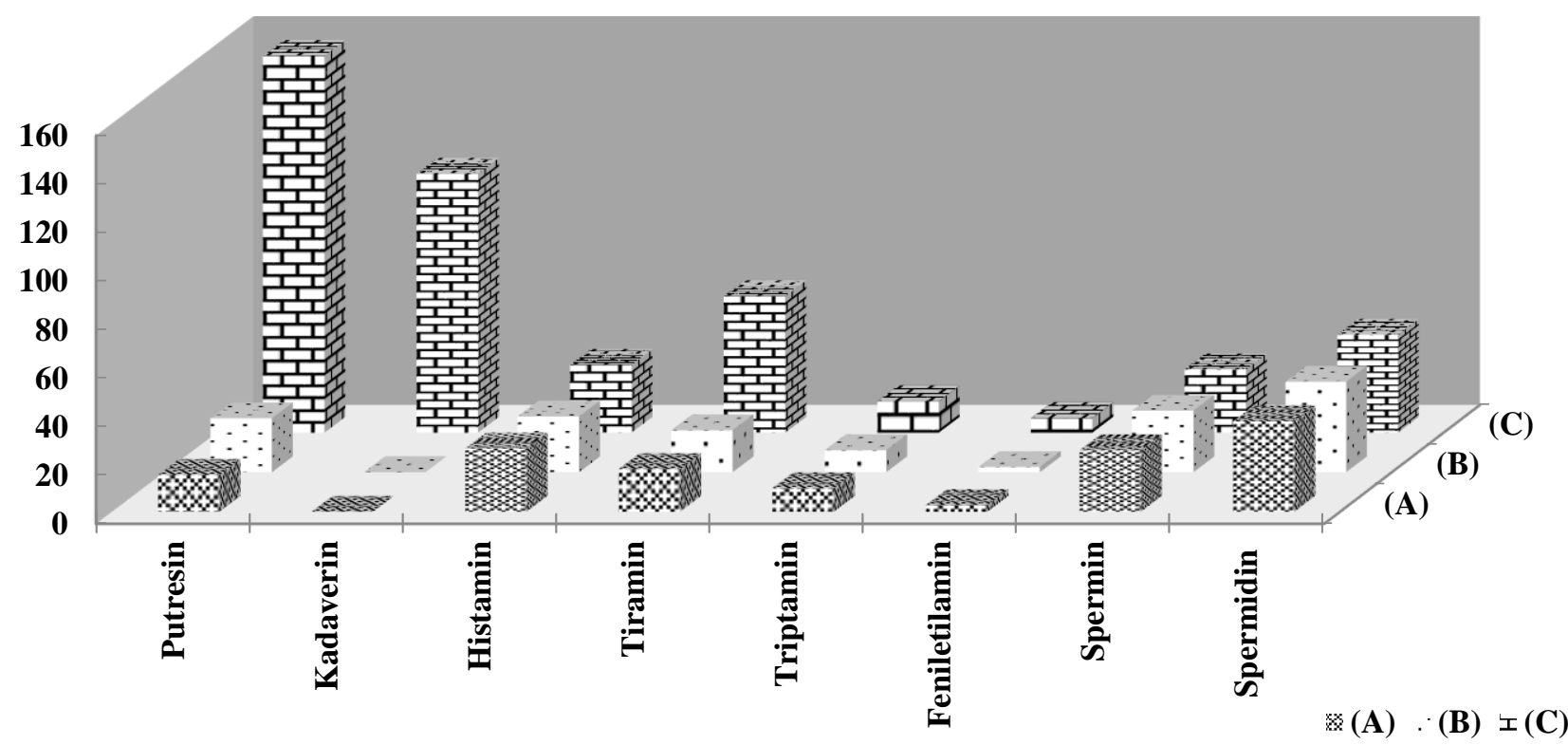

Şekil 1. Farklı Üretim Tekniğine Sahip Sucuk Gruplarının Biyojen Amin İçerikleri

Çalışmada piyasadan toplanılan kasap, endüstriyel tip fermente ve 1 sıl işlem görmüş sucuklarda yaklaşık \%90 oranında tespit edilen histamin sirasiyla $1.70-65.51 \mathrm{mg} / \mathrm{kg}, 2.61-58.75$ $\mathrm{mg} / \mathrm{kg}$ ve $0.18-61.03 \mathrm{mg} / \mathrm{kg}$ aralıklarında bulunmuştur (Tablo 1). Üretim yöntemi aynı olmasına rağmen sucukların histamin konsantrasyonlarındaki farkl1lıklar, ham maddenin hijyenik kalitesi ve belirli mikroorganizmaların varlığından kaynaklanabilmektedir (Ekici ve Omer, 2018). En düşük histamin konsantrasyonu $\mathrm{B}$ grubu 1 sıl işlem görmüş sucuklarda gözlenmiştir (Şekil 1) ve bu da ısıl işlem uygulamasıyla kısalan fermantasyon süresinin histamin oluşumunun azalmasına neden olduğu sonucunu doğrulamıştır (Kurt, 2006; Çelebi Sezer ve Bozkurt, 2019). İzin verilen maksimum histamin değeri sucuklar için 50-100 mg/kg olarak rapor edilmiştir (Nout, 1994). Benzer bir şekilde yapılan çalışmada piyasadan toplanılan sucuk örneklerinde en yüksek histamin değeri $65.51 \mathrm{mg} / \mathrm{kg}$ olarak C grubu kasap sucuklarında görülmüştür (Tablo 1). Triptamin ve feniletilaminin ortalama konsantrasyonları A, B ve C gruplarında sirasiyla $9.77,9.09,13.04 \mathrm{mg} / \mathrm{kg}$ ve $2.80,2.12,6.06 \mathrm{mg} / \mathrm{kg}$ şeklinde $(\mathrm{P}<0.05)$ görülmüştür. Biyojen amin değerlerinde görülen bu değişkenlikler, farklı üretim uygulamaları, ham madde özellikleri (et bileşimi, pH, su aktivitesi, serbest aminoasit düzeyi, tuz düzeyi, işleme koşulları, vb.), bakteri yoğunluğu, özellikle aminoasit dekarboksilaz aktiviteye sahip mikroorganizmalar (Lactobacilli, Enterococci, Micrococci ve Enterobacteriaceae familyasına ait mikroorganizmalar), mikroorganizmaların sinerjistik etkisi, kötü hijyenik koşullar, sıcaklık uygulamaları, depolama, olgunlaşma süresi ve starter kültür kullanımı gibi faktörlere bağlı olabilmektedir (Sivamaruthi ve ark. 2020). Geleneksel yöntem ile üretilen kasap sucuklarında uygulanan doğal fermantasyon işlemi kontrolsuz ve hijyenik olmayan ortamda gerçekleşebilmesi ve starter kültür kullanılmaması fazla miktarda biyojen amin birikmesine neden olmaktadır (Erkmen ve Bozkurt, 2004; Sivamaruthi ve ark. 2020). Diğer taraftan e-ISSN: 2148-2683 endüstriyel sucuklarda starter kültür kullanımı biyojen amin oluşumunu farklı şekillerde etkileyebilir. Negatif dekarboksilaz aktiviteye sahip starter kültürlerin kullanımının biyojen amin oluşumunu sınırlandırması ile ilgili literatürde pek çok çalıșma bulunmaktadır (Lu ve ark. 2010; Doeun ve ark. 2017; LatorreMoratalla ve ark. 2017; Sivamaruthi ve ark. 2020). Yapılan çalışmada starter kültür kullanılan endüstriyel fermente ve 1sıl işlem görmüş sucuk örneklerinde istatiksel olarak anlamlı derecede düşük seviyede gözlenmiştir (Tablo 2). Tüm sucuk örneklerinin spermin ve spermidin konsantrasyonları sirasıyla $22.34-42.54 \mathrm{mg} / \mathrm{kg}$ ve $36.52-44.70 \mathrm{mg} / \mathrm{kg}$ (Tablo 1) arasinda değișmektedir. Biyojen amin konsantrasyonlarında gözlenen bu farklılıklar, ette doğal olarak oluşan spermin ve spermidin ile bakteriyel amin üretimini etkileyen $\mathrm{pH}$, sıcaklık gibi önemli çevresel etkenlerden kaynaklanabilmektedir (Doeun ve ark. 2017; Sivamaruthi ve ark. 2020). Farklı üretim tekniklerinin kullanılmasının spermin ve spermidin konsantrasyonlarını istatistiksel olarak etkilemediği ( $(\mathrm{P}>0.05)$ görülmüştür (Tablo 2). Bunun nedeni olarak bu iki biyojen aminin doğal poliamin olması ve hayvan, bitki ve mikroorganizmalar tarafindan doğal olarak üretilebilmesinden kaynaklandığ 1 söylenebilir (Ruiz-Capillas ve Jiménez-Colmenero, 2005). Birçok araştırmacı, tiramin ve kadaverinin sucuktaki en önemli ve en çok bulunan biyojen amin olduğunu bildirmişlerdir (Rabie ve ark., 2011; Latorre-Moratalla ve ark. 2017; Ruiz-Capillas ve Herrero, 2019). Ekici ve Omer (2018) piyasadan toplanılan sucuklarda sirasiyla kadaverini $(23.8-681.2 \mathrm{mg} / \mathrm{kg})$ ardindan histamini $(0.87-343.91 \mathrm{mg} / \mathrm{kg})$ ve tiramini $(53.50-273.91 \mathrm{mg} / \mathrm{kg})$ değişen konsantrasyonlarda rapor etmişlerdir. Coïsson ve ark. (2004) İtalyan sucuklarında en yüksek biyojen amin konsantrasyonunu $372 \mathrm{mg} / \mathrm{kg}$ ile tiramin ve ardından $165 \mathrm{mg} / \mathrm{kg}$ ile histamin olarak belirtmişlerdir. Çalışmada analiz edilen sucuklarda kadaverin, putresin, tiramin konsantrasyonları diğer biyojen aminlere kıyasla yüksek değerlerde gözlenmiştir. Piyasadan toplanan sucukların biyojen 
amin miktarını bildiren literatürde pek çok çeşitli çalışma bulunmaktadır. Ankara'da yerel markette toplanılan sucuk örneklerinde kadaverin miktarı $514.24 \mathrm{mg} / \mathrm{kg}$ ve tiramin seviyesi 198.14 mg/kg'a kadar değişmiştir (Çoşansu ve Ayhan, 2002). Diğer taraftan Erkmen ve Bozkurt (2004) yapmış oldukları çalışmada endüstriyel tip fermente sucuklarda en yüksek putresin ve tiramin değerlerini sirasıyla 383.17 ve $188.6 \mathrm{mg} / \mathrm{kg}$ olarak bulmuşken, kasap sucuklarında bu değerler 918.94 ve 316.3 $\mathrm{mg} / \mathrm{kg}$ 'a kadar ulaşmıştır. Laktik asit bakterileri ve Gram pozitif kokların baskın flora olduğu İtalyan sucuklarında putresin değeri $2 \mathrm{mg} / \mathrm{kg}$ değerindeyken, tiramin konsantrasyonu $187 \mathrm{mg} / \mathrm{kg}$ şeklinde bulunmuştur (Ansorena ve ark., 2002). Gençcelep ve ark. (2008) ve Şenoz ve ark. (2000) sucuklarda tiramin içeriğini 2.4$676 \mathrm{mg} / \mathrm{kg}$ ve 208.66- $1173.28 \mathrm{mg} / \mathrm{kg}$ olduğu sonucuna varmışlardır. Biyojen amin için toplam 100-200 mg/kg kabul edilebilir bir düzey olarak bildirilmiştir (Nout, 1994). Yapılan çalışmada endüstriyel tip fabrika ve isıl işlem görmüş sucuk gruplarının biyojen amin konsantrasyonları bu değerler arasında yer almıştır. Ancak, kasap sucuklarının yaklaşık \%25'nde putresin değeri ve \%10'nda kadaverin değeri $200 \mathrm{mg} / \mathrm{kg}$ değerini aşmıştır (Tablo 1). Bunun nedeni yukarıda belirtildiği gibi kontrolsüz ve hijyenik olmayan şartlarda üretim, starter kültür kullanılmaması ve 1sıl işlem uygulanmaması gibi nedenler gösterilebilir (Erkmen ve Bozkurt, 2004; Latorre-Moratalla ve ark. 2017; Sivamaruthi ve ark. 2020).

Et ürünlerinde biyojen amin konsantrasyonları için kabul edilebilir sınırlandırmalar ve yaptırımlara ilişkin özel bir mevzuat genel olarak mevcut değildir (Ruiz-Capillas ve JiménezColmenero, 2005; Ekici ve Omer, 2018). Toksik doz, her bireyin detoksifikasyon mekanizmalarının etkinliğine büyük ölçüde bağlı olduğu için, bireylerde biyojen aminlerin kesin toksisite eşiğinin belirlenmesi son derece zordur. Biyojen aminlerin insanlar üzerindeki toksisitesi tartışmalı bir konu olmasına rağmen, 70 ile $1000 \mathrm{mg}$ histaminin alınması genellikle klinik semptomlara neden olduğu rapor edilmiştir (Ekici ve Omer, 2018). Bununla birlikte bazı bilim insanları histamin alımının toksik etkisini sınıflandırmış ve $8-40 \mathrm{mg}$ arası hafif zehirlenmeye neden olabileceğini bildirmişlerdir (Doeun ve ark. 2017). Bu nedenle histamin, toksik etkisi en yüksek olan biyojen amindir (Doeun ve ark. 2017). Çalışmada A, B ve C grup sucuklarının sırasıyla yaklaşık \% 40, \%30 ve \%35'i $40 \mathrm{mg} / \mathrm{kg}^{\prime}$ dan daha yüksek histamin konsantrasyonuna sahiptir (Tablo 1). Erkmen ve Bozkurt'un (2004) yapmış olduğu bir çalışmada endüstriyel tip fermente ve kasap sucuk örneklerinin sirasıyla yaklaşık olarak \%31.6 ve \% 32.3 'nde $100 \mathrm{mg} / \mathrm{kg}$ 'den daha yüksek histamin konsantrasyonu tespit edilmişken, Gençcelep (2008) yaptığı başka bir çalışmada sucuk örneklerinin \%17'sinde histamin değeri 50-100 mg/kg olarak tespit edilmiştir. Amerikan Gıda ve İlaç Dairesi (FDA), ton balığındaki histamin için risk konsantrasyonu olarak $50 \mathrm{mg} / 100$ g olarak bildirmiştir (Ekici ve Omer, 2018). Diğer biyojen aminlerden putresin (2000 mg/kg), kadaverin (2000 mg/kg), triptamin $(2000 \mathrm{mg} / \mathrm{kg})$, spermin $(600 \mathrm{mg} / \mathrm{kg})$ ve spermidin $(600$ $\mathrm{mg} / \mathrm{kg}$ ) için oral toksisite seviyeleri şeklinde bildirilmiştir (Til ve ark., 1997; Naila ve ark., 2011). Buna rağmen başka bir çalışmada putresinin toksik etkisi bulunmamakla birlikte kadaverin ile birlikte histamin ve tiraminin toksik etkisini arttırdığ edilmiştir (Ansorena ve ark., 2002). Ayrıca, daha az miktarlarda biyojen amin alımlarının da, kişisel yatkınlık, gastrointestinal hastalıklar, bazı ilaçların kullanımı ve alkol alımı gibi nedenlerle vücuttaki biyojen aminlerin detoksifikasyon mekanizmasının engellenmesiyle zehirlenmeye neden olabileceği unutulmamalıdır (Ekici ve Omer, 2018). Diğer taraftan, $6 \mathrm{mg}$ veya 50-100 mg gibi düşük tiramin alımları, MAOI (Monoamin oksidaz inhibitörleri) ilaçları ile tedavi edilen hastalarda hipertansif belirtilere neden olabildiği bildirilmiş (Latorre-Moratalla ve ark., 2008) ve ilaç tedavisi gören kişiler için fermente sucuk tüketiminin sınırlandırılması gerektiği vurgulanmıştır (Ekici ve Omer, 2018).

İyi Üretim Uygulamaları (GMP) insan sağlığını etkileyen ürünlerin güvenilir koşullarda üretilmesi ve tüketiciye ulaşmasına kadarki süreçte kontaminasyon riskinin önüne geçmek için bir dizi koruyucu önlemler olarak bildirilmiştir (Rossi ve ark. 2018) Shalaby (1996) ürünlerde İyi Üretim Uygulamaları (GMP) değerlendirilmesi yapılabilmesi için biyojen amin konsantrasyonlarının (tiramin 100-800 mg/kg, histamin 50-100 $\mathrm{mg} / \mathrm{kg}$, feniletilamin $<30 \mathrm{mg} / \mathrm{kg}$ ) önerilen miktarlarda bulunmas gerektiğini bildirmiştir. Çalışmada tespit edilen maksimum histamine, tiramin ve feniletilamin konsantrasyonları tavsiye edilen miktarlara göre oldukça düşük bulunmuştur.

\section{Sonuç}

Genel olarak, kasap sucuklarının ısıl işlem ve endüstriyel tip fermente sucuklardan biyojen amin miktarı açısından daha yüksek olduğu tespit edilmiştir. Bu sonuçlar, starter kültür kullanılmadan gerçekleştirilen doğal fermantasyon işleminin sucuklar da yüksek oranda biyojen amin birikmesine neden olabileceğini göstermektedir. Gelişmiş, hijyenik koşullar barındıran modern tesisler de üretimin gerçekleşmesi ve negatif dekarboksilaz aktiviteye sahip starter kültürlerin kullanılması ile biyojen aminlerin oluşumunun engellenmesi veya azaltılması mümkün olabilecektir. Bununla birlikte 1sıl işlem uygulanmasının biyojen amin oluşumunun kontrol altına alınmasında ayrı bir öneme sahip olduğu açıkça görülmektedir. Diğer taraftan, ulusal biyojen amin toksik limitleri belirlenmeli ve yasallaştırılarak kanuni yaptırımları oluşturulmalıdır. Bununla birlikte tüketiciler için farkındalık oluşturabilmek adına ürün etiketleme bilgileri düzenlenmelidir.

\section{Kaynakça}

Ansorena, D., Montel, M. C., Rokka, M., Talon, R., Eerola, S., Rizzo, A., \& Demeyer, D. (2002). Analysis of biogenic amines in northern and southern European sausages and role of flora in amine production. Meat Science, 61(2), 141-147.

Ayhan, K., Kolsarici, N., Özkan, G. A. (1999). The effects of a starter culture on the formation of biogenic amines in Turkish soudjoucks. Meat Science, 53(3), 183-188.

Blagojevic, B., Antic, D., Adzic, B., Tasic, T., Ikonic, P., \& Buncic, S. (2015). Decontamination of incoming beef trimmings with hot lactic acid solution to improve microbial safety of resulting dry fermented sausages-A pilot study. Food Control, 54, 144-149.

Bover-Cid, S., Schoppen, S., Izquierdo-Pulido, M., Vidal-Carou, M. (1999). Relationship between biogenic amine contents and the size of dry fermented sausages. Meat Science, 51 (4) 305-311.

Bozkurt, H. ve Erkmen, O. (2002). Effects of starter cultures and additives on the quality of Turkish style sausage (sucuk). Meat Science, 61 (2) 149-156.

Coïsson, J. D., Cerutti, C., Travaglia, F., \& Arlorio, M. (2004). Production of biogenic amines in "Salamini italiani alla cacciatora PDO". Meat Science, 67(2), 343-349.

Coloretti, F., Tabanelli, G., Chiavari, C., Lanciotti, R., Grazia, L., Gardini, F., \& Montanari, C. (2014). Effect of wine addition on microbiological characteristics, volatile molecule profiles 
and biogenic amine contents in fermented sausages. Meat science, 96(3), 1395-1402.

Çoşansu, S. ve Ayhan, K. (2002). Ankara'da satışa sunulan sucukların biyojen içerikleri. Türkiye 7. Gıda Kongresi, 2224 May1s, 453, Ankara.

Çelebi Sezer, Y., Bozkurt, H. (2019). Use of novel casing in sucuk production: Antimicrobials incorporated into multilayer plastic film. Acta Alimentaria, 48(1), 1-8.

Değirmencioğlu, A., Arslan M., Gökgözoğlu İ. ve Tavşanlı H. (2006). Klasik Tip Ve Isıl İşlem Uygulanarak Olgunlaştırılan Sucukların Özelliklerindeki Değişimlerin Belirlenmesi Üzerine Bir Araştırma. Türkiye 9. Gıda Kongresi, 24-26 Mayıs, Bolu, 401-2.

Demirgül, F., Sağdıç, O. (2017). Laktik starter kültür üretim teknolojisi. Avrupa Bilim ve Teknoloji Dergisi, 7(11), 27-37.

Doeun, D., Davaatseren, M., \& Chung, M. S. (2017). Biogenic amines in foods. Food science and biotechnology, 26 (6), 1463-1474

Domínguez, R., Munekata, P. E., Agregan, R., \& Lorenzo, J. M. (2016). Effect of commercial starter cultures on free amino acid, biogenic amine and free fatty acid contents in dry-cured foal sausage. LWT-Food Science and Technology, 71, 47-53.

Eerola, S., Hinkkanen, R., Lindfors, E., Hirvi, T. (1993). Liquid chromatographic determination of biogenic amines in dry sausages. Journal of AOAC International, 76(3), 575-577.

Ekici, K. ve Omer, A. K. (2018). The determination of some biogenic amines in Turkish fermented sausages consumed in Van. Toxicology reports, 5, 639-643.

Ekici, K., Şekeroğlu, R., Sancak, Y. C., Noyan, T. (2004). A note on histamine levels in Turkish style fermented sausages. Meat science, 68(1), 123-125.

Ensoy, U., Kolsarici, N., Candoğan, K., \& Karslıŏlu, B. (2010). Changes in biochemical and microbiological characteristics of turkey sucuks as affected by processing and starter culture utilization. Journal of Muscle Foods, 21(1), 142-165.

Erkmen, O. (1999). Behavior of Staphylococcus aureus in Refrigerated and Frozen Ground Beef and in Turkish Style Sausage and Broth With and Without Additives. Journal of Food Processing and Preservation, 21, 279-288.

Erkmen, O. ve Bozkurt, H. (2004). Quality characteristics of retailed sucuk (Turkish Dry-Fermented Sausage). Food Technology and Biotechnology, 42, 63-69.

Gençcelep, H., Kaban, G., Aksu, M. İ., Öz, F., Kaya, M. (2008). Determination of biogenic amines in sucuk. Food Control, 19(9), 868-872.

Kara, R. ve Akkaya, L. (2010). Geleneksel ve Isıl işlem Uygulanarak Üretilen Türk Sucuklarında Salmonella typhimurium'un Gelişimi. Gıda Teknolojileri Elektronik Dergisi, 5(3), 1-8.

Kesmen, Z., Yarimcam, B., Aslan, H., Ozbekar, E., \& Yetim, H. (2014). Application of different molecular techniques for characterization of catalase-positive cocci isolated from Sucuk. Journal of food science, 79(2), M222-M229.

Kim, M., Jae-Mah, J., Hwang, H. (2009). Biogenic amine formation and bacterial contribution in fish, squid and shellfish. Food Chemistry, 116, 87-95.

Kurt Ş. (2006). The effects of fermentation time, nitrite level and heat treatment on biogenic amine formation and some properties of sucuk. PhD thesis. Yüzüncü Y1l University, Van, Turkey.

Kurt, Ş. ve Zorba, Ö. (2010). Biogenic amine formation in Turkish dry fermented sausage (sucuk) as affected by nisin and nitrite. J. Sci. Food Agric, 90 (15) 2669-2674.
Latorre-Moratalla, M. L., Veciana-Nogués, T., Bover-Cid, S., Garriga, M., Aymerich, T., Zanardi, E., ... \& Laukova, A. (2008). Biogenic amines in traditional fermented sausages produced in selected European countries. Food Chemistry, 107(2), 912-921.

Latorre-Moratalla, M. L., Comas-Basté, O., Bover-Cid, S., \& Vidal-Carou, M. C. (2017). Tyramine and histamine risk assessment related to consumption of dry fermented sausages by the Spanish population. Food and Chemical Toxicology, $99,78-85$.

Lu, S., Ji, H., Wang, Q., Li, B., Li, K., Xu, C., \& Jiang, C. (2015). The effects of starter cultures and plant extracts on the biogenic amine accumulation in traditional Chinese smoked horsemeat sausages. Food Control, 50, 869-875.

Lu, S., Xu, X., Zhou, G., Zhu, Z., Meng, Y., Sun, Y. (2010). Effect of starter cultures on microbial ecosystem and biogenic amines in fermented sausage. Food Control, 21: 444-449.

Naila, A., Flint, S., Fletcher, G. C., Bremer, P. J., \& Meerdink, G. (2011). Biogenic amines and potential histamine-forming bacteria in rihakuru (a cooked fish paste). Food chemistry, 128(2), 479-484.

Nout, M. (1994). Fermented foods and food safety. Food Res. Int., 27 (3), 291-298.

Önal, A. (2007). A review: current analytical methods for the determination of biogenic amines in foods. Food Chemistry, 103 (4) $1475-1486$.

Papavergou, E. J. (2011). Biogenic amine levels in dry fermented sausages produced and sold in Greece. Procedia Food Science, 1, 1126-1131.

Rabie, M. Elsaidy, S. el-Badawy, A. Siliha, H. Malcata, F. (2011). Biogenic amine contents in selected Egyptian fermented foods as determined by ion-exchange chromatography. J. Food Prot., 74 (4) 681-685.

Rossi, E. M., Beilke, L., \& Barreto, J. F. (2018). Microbial contamination and good manufacturing practices in school kitchen. Journal of food safety, 38(1), e12417.

Ruiz-Capillas, C., Jiménez-Colmenero, F. (2005). Biogenic amines in meat and meat products. Critical Reviews in food Scince and Nutrition, 44(7-8), 489-599.

Ruiz-Capillas, C., Herrero, A. M. (2019). Impact of biogenic amines on food quality and safety. Foods, 8(2), 62.

Şenoz, B., Isıklı, N., Coksoyler, N. (2000). Biogenic amines in Turkish sausages (sucuks). Journal of Food Science, 65(5), 764-767.

Shalaby, A. R. (1996). Significance of biogenic amines to food safety and human health. Food Research International, 29(7), 675-690.

Sivamaruthi, B. S., Kesika, P., \& Chaiyasut, C. (2020). A narrative review on biogenic amines in fermented fish and meat products. Journal of Food Science and Technology, 1-17.

Stadnik, J. and Dolatowski, Z. J. (2010). Biogenic amines in meat and fermented meat products. Acta. Sci. Pol. Technol. Aliment., 9 (3), 251-263.

Stojanović Z. ve Švarc-Gajić, J. (2011). A simple and rapid method for histamine determination in fermented sausages by mediated chronopotentiometry. Food Control, 22 (12), 2013 2019.

Suzzi, G. ve Gardini F. (2003). Biogenic amines in dry fermented sausages: a review. Int J Food Microbiol, 88, 41-54.

Til, H. P., Falke, H. E., Prinsen, M. K., \& Willems, M. I. (1997). Acute and subacute toxicity of tyramine, spermidine, spermine, putrescine and cadaverine in rats. Food and Chemical Toxicology, 35(3-4), 337-348. 
Vidal-Carou M.C., Veciana-Nogués T., Lattore-Moratalla M.L. and Bover-Cid S. (2007). "Biogenic amines: Risks and control", In: Toldrá F. (Eds). Handbook of fermented meat and poultry, Ames, Iowa, USA: Blackwell Publishing Inc, 455-468.

Yıldırım, Y. (1996). "Et Endüstrisi”. Uludağ Ü. Veteriner Fak., Kozan Ofset (4. Baskı), Ankara. 